\title{
Simulating typhoon-induced storm hydrographs in subtropical mountainous watershed: an integrated 3-layer TOPMODEL
}

\author{
J.-C. Huang ${ }^{1}$, T.-Y. Lee ${ }^{1,2}$, and S.-J. Kao ${ }^{1,3}$ \\ ${ }^{1}$ Research Center for Environmental Changes, Academia Sinica, Taipei, Taiwan \\ ${ }^{2}$ Department of Bioenvironmental Systems Engineering, National Taiwan University, Taipei, Taiwan \\ ${ }^{3}$ State Key Laboratory of Marine Environmental Science, Xiamen University, Xiamen, China
}

Received: 20 February 2008 - Published in Hydrol. Earth Syst. Sci. Discuss.: 21 April 2008

Revised: 3 December 2008 - Accepted: 13 December 2008 - Published: 23 January 2009

\begin{abstract}
A three-layer TOPMODEL is constructed by integrating diffusion wave approach into surface flow, soil moisture deficit into inter flow and exponential recession curve function into base flow. A subtropical mountainous watershed, Heng-Chi, and 22 rain storms with various rainfall types and wide ranges of total rainfall (from 81 to $1026 \mathrm{~mm}$ ) were applied. The global best-fitted parameter set gives an average efficient coefficient of $82 \%$ for calibration and $80 \%$ for validation. Sensitivity analysis reveals that soil transmissivity dominates the discharge volume and recession coefficient dominates the hydrograph shape in TOPMODEL framework. Over $90 \%$ observed discharges of validation events falls within the $90 \%$ confidence interval derived form calibration events. The resembling performances between calibration and validation as well as good results of the confidence interval demonstrate the capability of 3-layer TOPMODEL on simulating cyclones with various rainfall intensity and pattern in subtropical watershed. Meanwhile, the upper confidence limit is suggested preferably when considering flood assessment.
\end{abstract}

\section{Introduction}

Taiwan, sitting on the Pacific Fault (orogenic belt), forested and precipitous landscape (mountainous area) occupies about $67 \%$ of the whole island. Meanwhile, the island also locates on the typhoon alley of the Western Pacific and it suffers frequent typhoons, about 3-5 typhoon invasions every summer (Taiwan Central Weather Bureau, www.cwb.gov.tw). Coupled with steep landscape and frac-

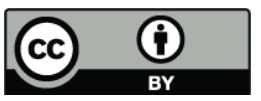

Correspondence to: S.-J. Kao

(sjkao@gate.sinica.edu.tw) ture rocks, typhoon generally indicates debris flows and landslides at the upstream and flood at downstream areas (Huang et al., 2007). For instances, Typhoon Herb in 1996, Zeb in 1998 and Xangsane in 2000 brought over $800 \mathrm{~mm}$ rainfall within two days. Typhoon Nari in 2001 broke the record by bringing $1026 \mathrm{~mm}$ rainfall within 2 days with intensity over $50 \mathrm{~mm} / \mathrm{h}$ in certain hours. During Nari typhoon period, more than 400 landslides were triggered in Taipei Basin and the low land city areas were severely flooded (Sui et al., 2002). This single event took 94 human lives and caused about 300 million US \$ economic loss. Typhoon-induced hazards threaten human lives and cause an average annual loss of more than 500 million US \$ due to agricultural, economical, and infrastructure damages (Li et al., 2005).

To cope with those threats induced by typhoon, simulating hydrological responses (e.g. stream discharge) is thus one of the major concerns for hazard mitigation and water resource management in Taiwan. This issue becomes more imperative because both the frequency and intensity of Western Pacific cyclone are increasing (Wu et al., 2005). Unavoidably, Taiwan and other regions in East Asia will suffer a greater pressure of typhoon. Thus, a suitable hydrological model is urgently needed.

However, to simulate the dramatic hydrological responses in forested mountainous watersheds in Taiwan is challenging due to fracture geologic setting and meteorological conditions. A popular watershed modeling tool, TOPMODEL, has been demonstrated applicable to a wide variety of climates and landscapes (e.g. Beven, 1997, 2001; Lamb et al., 1998; Scanlon et al., 2000) because of its simplicity and clever use of geomorphology. TOPMODEL links the topographic index and recession curve function by catchment storage concept and as a result, the stream discharge and spatial pattern of water table deficit (or soil wetness) can be simulated simultaneously. The latter part can also be incorporated into

Published by Copernicus Publications on behalf of the European Geosciences Union. 
landslide modeling (Casadei et al., 2003; Huang et al., 2006). Therefore, it may be a conformable choice to concern both tasks at the same time (e.g. landsliding and flooding).

As applying TOPMODEL concept to simulate the stream discharge, many geochemical studies indicated that separating subsurface flow into inter flow and base flow may be plausible in many conditions particularly for short and intensive rainfall (e.g. humid tropical climate by Campling et al., 2002; mediterranean climate by Candela et al., 2005). Moreover, various modifications for subsurface flows had been proposed, such as Scanlon et al. (2000), Hornberger et al. (2001) and Walter et al. (2002). On the other hand, in order to improve the estimation of surface flow convolution, routing procedure had also been introduced into TOPMODEL to specify the drainage path and travel time of each cell (Candela et al., 2005). As aforementioned, typhoon invades Taiwan aperiodically in summer when soil is dry and water discharge is low. However, rare studies documented TOPMODEL performance for frequent typhoon-induced extreme rainfall storms in subtropical region and none of the applications has ever been integrated with advanced modifications mentioned above as a whole.

Here, we construct a 3-layer TOPMODEL through integrating previous modifications and apply it onto a subtropical small mountainous watershed, particularly for simulating flood discharges caused by typhoons. One small watershed, Heng-Chi, at northern Taiwan, was undertaken. A total of 22 rain storms during 1990-2004 were selected as 11 of them were for calibration and the rest for validation. Meanwhile, sensitivity analysis was carried out to unravel major controlling parameters and the interactions of the three flows (surface flow, inter flow, and base flow). Finally, we compared all observed discharges with simulated discharges throughout all calibration events to extract the confidence interval. Hopefully, the entire procedure would advance the understanding of model structure and support decision-making in hazard mitigation program.

\section{Materials}

\subsection{Study area}

The climate in northern Taiwan is characterized by wet winters and dry summers with frequent typhoons during July to September. Average annual precipitation varies from 2500 to $3100 \mathrm{~mm}$ and the monthly mean temperature ranges from $13^{\circ} \mathrm{C}$ in January to $28^{\circ} \mathrm{C}$ in July (Taiwan Central Weather Bureau).

Heng-Chi with a drainage area of $52 \mathrm{~km}^{2}$ is a tributary of Danshusi River, which flows through Taipei City where over 2.65 million residents live. High population density in Taipei City underscores the importance of hydrological modeling for upstream tributaries that may contribute to downstream flood warning and hazard mitigation. The main stream originates from Xiong-Kong Mt. (960 m a.s.l.) with its elevation from 180 to $960 \mathrm{~m}$ and an average slope of $41 \%$. The topographic map and gauging stations are shown in Fig. 1. One hydrological station and only one rainfall station inside the watershed are maintained by the Water Resource Agency (www.wra.gov.tw).

The geologic setting in Heng-Chi watershed is mainly composed of sandstone and shale (Taiwan Central Geological Survey, www.moeacgs.gov.tw). Strong weathering and erosion result in steep and deeply dissected landscape. Slopelands and low hills veneered by gravelly and sandy loam soils occupy $\sim 90 \%$ of the watershed. Most rice fields and scattered farm houses are located in the gentle slopes at lower elevation while shrubbery, bamboo and primeval forest take up the slopes at higher elevation.

\subsection{Extreme rain storms and flood events}

22 storm events are selected for this study (Table 1). Total rainfall among events ranges from 81 to $1026 \mathrm{~mm}$ with an average rainfall intensity of $5.7-24.9 \mathrm{~mm} / \mathrm{h}$ and the maximum rainfall intensity of $22-98 \mathrm{~mm} / \mathrm{h}$. Overall speaking, cumulative rainfalls are over $322 \mathrm{~mm}$ within $33 \mathrm{~h}$. The total discharge ranges from 1.8 to $26.710^{6} \mathrm{~m}^{3}$ positively correlated to total rainfall and rainfall duration. The peak flows range from 57.8 to $526.7 \mathrm{~m}^{3} / \mathrm{s}$ being positively correlated with total rainfall, average rainfall intensity, and maximum rainfall intensity (Table 1).

Water discharge responds rapidly to rainfall with short time lag (generally less than $2 \mathrm{~h}$ ). In most cases, the discharge surges approximately 100 times, from $<2 \mathrm{~m}^{3} / \mathrm{s}$ to $>200 \mathrm{~m}^{3} / \mathrm{s}$ within one hour. To investigate the model capability for unknown events, the 22 events are separated equally into two subsets by total rainfall. That is, 11 events are for calibration and 11 events for validation. Each subset consists of similar range of total rainfall.

\section{Methods}

\subsection{Three-layer structure and model formulation}

The three-layer TOPMODEL contains eight processes: precipitation, evapotranspiration, interception, infiltration, percolation, surface flow, inter flow and base flow (see Fig. 2). Storage organization consists of three layers: 1) the upper layer, that is, the Root Zone, which has a fixed maximum water storage capacity, $S_{1 \max }[\mathrm{L}]$, and state variable of upper layer storage, $S_{1}[\mathrm{~L}] ; 2$ ) the middle layer, which is the conventional Unsaturated Zone between ground surface and the ground water table, with soil moisture deficit, $S_{2},[\mathrm{~L}]$ as state variable; 3 ) the bottom layer, the Saturated Zone, below the ground water table with $S_{3}[\mathrm{~L}]$ as its storage. The three state variables are used to regulate the surface flow $\left(Q_{S}\right)$, inter flow $\left(Q_{i}\right)$ and base flow $\left(Q_{b}\right)$. Relations among vertical flow, horizontal flow and state variables are illustrated below. 


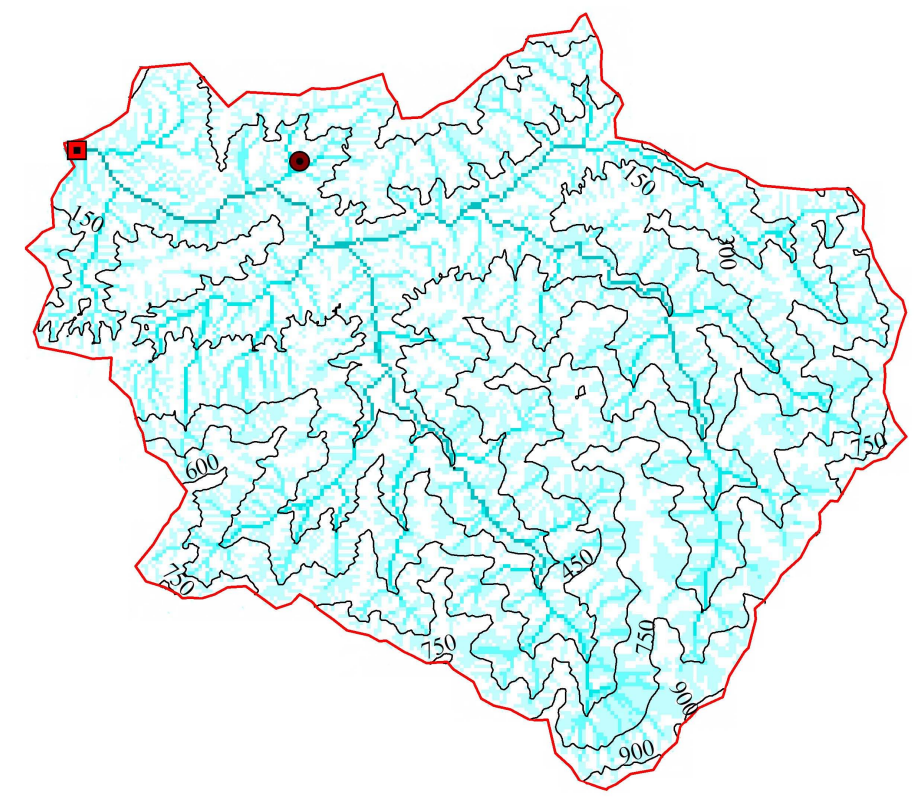

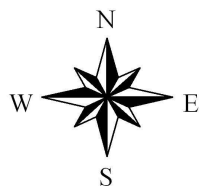

- rain gauge

a flow station

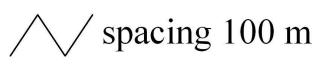

$\log (\mathrm{SCA})$

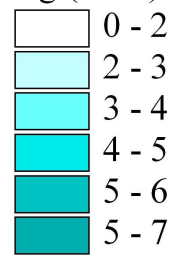

0

6 Kilometers

Fig. 1. The Heng-Chi watershed. Stream network, elevation contour, specific contributing area (SCA) and hydrological stations are presented.

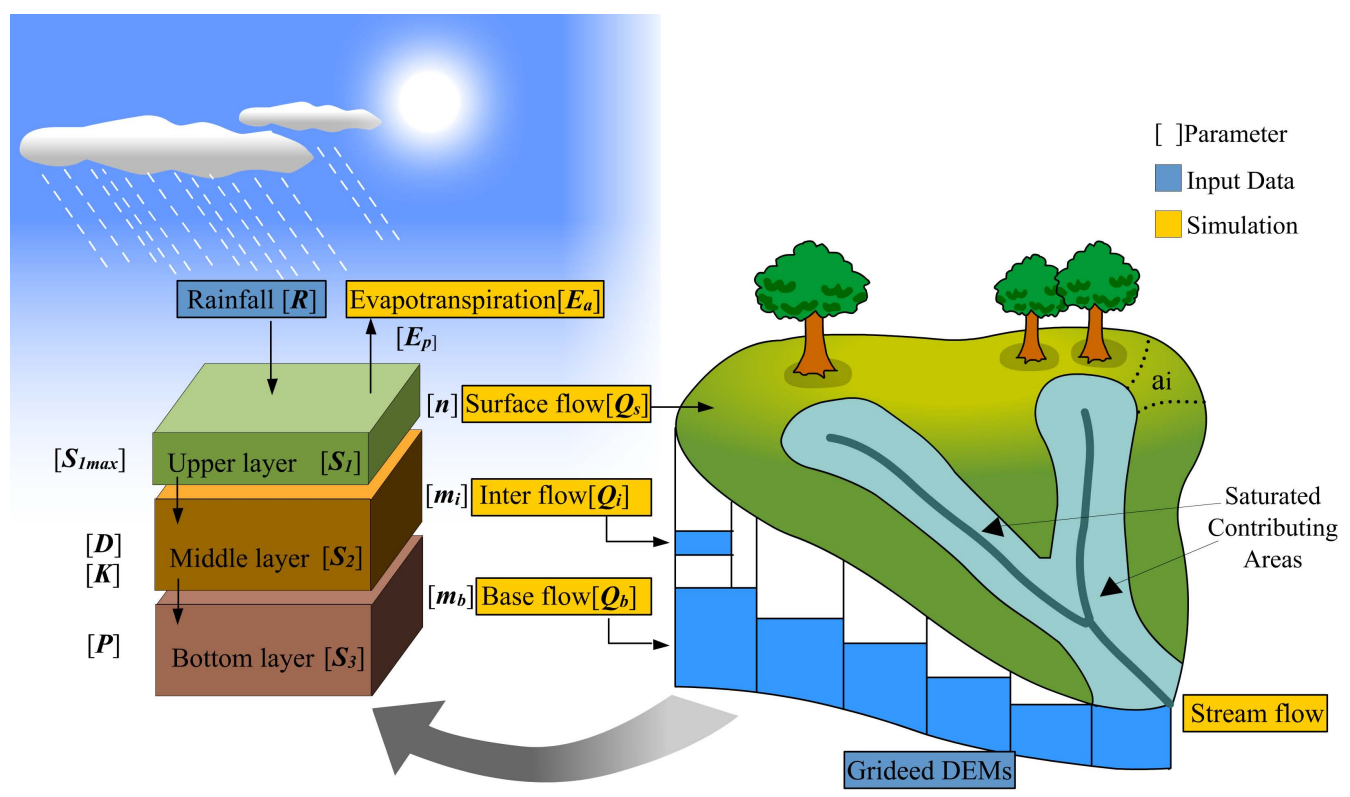

Fig. 2. Schematic diagram of the 3-layer TOPMODEL.

Once the rain falls, it is initially stored in the upper layer, where evapotranspiration occurs. The storage in the upper layer, $S_{1}$, is controlled by rainfall and actual evapotranspiration $\left(E_{a}\right)$, which is determined by the ratio of $S_{1}$ to $S_{1 \max }$ and potential evapotranspiration $\left(E_{p}\right)$.
The $E_{a}[\mathrm{~L} / \mathrm{T}]$ estimation is

$$
\begin{array}{ll}
E_{a}=E_{p} \frac{S_{1}}{S_{1 \max }}, & \text { if } \quad S_{1}<S_{1 \max } \\
E_{a}=E_{p}, \quad \text { if } & S_{1}>S_{1 \max .} .
\end{array}
$$


Table 1. The rainfall-runoff characteristics of the 22 events during 1990 2004.

\begin{tabular}{|c|c|c|c|c|c|c|c|c|c|}
\hline Event & Typhoon name & Date & $\begin{array}{l}\text { Rainfall } \\
(\mathrm{mm})\end{array}$ & $\begin{array}{l}\text { Rainfall } \\
\text { duration } \\
\text { (h) }\end{array}$ & $\begin{array}{l}\text { Avg. RI } \\
(\mathrm{mm} / \mathrm{h})\end{array}$ & $\begin{array}{l}\text { Max. RI } \\
(\mathrm{mm} / \mathrm{h})\end{array}$ & $\begin{array}{r}\text { Total } \\
\text { discharge } \\
\left(10^{6} \mathrm{~m}^{3}\right)\end{array}$ & $\begin{array}{r}\text { Peak } \\
\text { flow } \\
\left(\mathrm{m}^{3} / \mathrm{s}\right)\end{array}$ & $\begin{array}{r}\text { Lag } \\
\text { time } \\
(\mathrm{h})\end{array}$ \\
\hline No. 1 & Yancy & 18 Aug 1990 & 342 & 44 & 7.8 & 48 & 11.4 & 233.9 & 1 \\
\hline No. 2 & Storm & 19 Jun 1991 & 312 & 26 & 12.0 & 71 & 10.2 & 212.2 & 2 \\
\hline No. 3 & Polly & 27 Aug 1992 & 500 & 77 & 6.5 & 21 & 19.3 & 149 & 1 \\
\hline No. 4 & Storm & 3 Jun 1993 & 221 & 19 & 11.6 & 54 & 8.1 & 179 & 1 \\
\hline No. 5 & Doug & 7 Aug 1994 & 225 & 28 & 8.0 & 47 & 6.9 & 120 & 1 \\
\hline No. 6 & Herb & $30 \mathrm{Jul} 1996$ & 450 & 42 & 10.7 & 31 & 10.8 & 231.2 & 2 \\
\hline No. 7 & Zeb & 15 Oct 1998 & 475 & 36 & 13.2 & 36 & 14.7 & 174.0 & $<1$ \\
\hline No. 8 & Prapiroon & 26 Aug 2000 & 81 & 8 & 10.1 & 35 & 2.6 & 65.4 & 1 \\
\hline No. 9 & Prapiroon & 28 Aug 2000 & 204 & 36 & 5.7 & 25 & 6.8 & 57.8 & 2 \\
\hline No. 10 & Strom & 16 Jun 2001 & 125 & 6 & 20.8 & 61 & 1.8 & 167.9 & 1 \\
\hline No. 11 & Haima & 11 Sep 2004 & 486 & 46 & 10.6 & 33 & 15.0 & 218.8 & $<1$ \\
\hline *No. 12 & Ofelia & 23 Jun 1990 & 131 & 35 & 3.7 & 24 & 6.2 & 172.0 & 2 \\
\hline *No. 13 & Abe & 30 Aug 1990 & 316 & 24 & 13.2 & 51 & 10.4 & 310.4 & 1 \\
\hline *No. 14 & Dot & 7 Sep 1990 & 252 & 44 & 5.7 & 20 & 9.5 & 150.4 & $<1$ \\
\hline *No. 15 & Ellie & 17 Aug 1991 & 210 & 23 & 9.1 & 29 & 7.6 & 126.0 & $<1$ \\
\hline *No. 16 & Gladys & 31 Aug 1994 & 398 & 16 & 24.9 & 98 & 9.3 & 365.2 & 4 \\
\hline *No. 17 & Winnie & 17 Aug 1997 & 223 & 32 & 7.0 & 22 & 5.7 & 136.8 & 8 \\
\hline *No. 18 & Storm & 4 Oct 1998 & 306 & 52 & 5.9 & 28 & 7.7 & 113.9 & 1 \\
\hline *No. 19 & Storm & 17 Jun 1999 & 184 & 10 & 18.4 & 43 & 8.2 & 176.7 & 1 \\
\hline *No. 20 & Xangsane & 31 Oct 2000 & 508 & 46 & 11.0 & 33 & 18.3 & 387.8 & 2 \\
\hline *No. 21 & Nari & 16 Sep 2001 & 1026 & 62 & 16.5 & 58 & 26.7 & 526.7 & 2 \\
\hline *No. 22 & Mindulle & 4 Jul 2004 & 114 & 10 & 11.4 & 30 & 3.2 & 154.3 & 2 \\
\hline Avg. & - & - & 322 & 32.8 & 11.1 & 40.8 & 10.0 & 201.3 & $<2$ \\
\hline
\end{tabular}

\# RI indicates rainfall intensity; ${ }^{*}$ validation case.

The potential evapotranspiration can be determined by many methods (e.g. Penman, 1948; Monteith, 1965). Various factors such as temperature, wind speed, latitude, solar radiation, etc. are taken into account in certain methods. Although considering more factors in estimation might give better results in some circumstances, yet, it implies additional measurements, extra cost, and higher level of model complexity. To reduce the complexity, we applied the simple empirical approximation by using temperature and latitude (Hamon, 1961). For event-based simulations, the potential evapotranspiration estimation is neglected due to the much lower proportion between evapotranspiration to rainfall. Once $S_{1}$ exceeds $S_{1 \text { max }}$ due to rainfall, the excess, $q_{R}[\mathrm{~L}]$, may have two paths. One is to infiltrate vertically down into the middle layer to increase soil moisture, $q_{R, v}$ and the other one is to form surface flow, $q_{R h}$ depending on the middle layer is fully saturated or not. Once the middle layer is saturated, a vertical flux, $P$, percolates into the bottom layer from middle layer to elevate $S_{3}$. In each time step, $S_{2}$ and $S_{3}$ are used to calculate, respectively, the $Q_{i}$ and $Q_{b}$. The routing calculations of the surface flow, inter flow and base flow are described below.

For surface flow, the flow path unit response function (Eq. 2) proposed by Liu et al., (2003) was applied. Note that Mannings' equation and energy dissipation theory (Molnar and Ramirez, 1998) were embedded to approach diffusion wave solution approximately.

The approximate solution is

$U(t)=\frac{1}{\sigma \sqrt{2 \pi \cdot t^{3} / t_{0}^{3}}} \exp \left[-\frac{\left(t-t_{0}\right)^{2}}{2 \pi t / t_{0}}\right]$,

and the outlet flow hydrograph can be represented as

$Q_{S}(t)=\int_{A} \int_{0}^{t} q_{R h}(\tau) \cdot U(t-\tau) d \tau d A$,

where $U(t)[1 / \mathrm{T}]$ is the flow path unit response function; $t_{0}$ $[\mathrm{T}]$ is the average travel time of the cell to outlet along flow path and $\sigma[\mathrm{T}]$ is the standard deviation of travel time. Both parameters, $t_{0}$ and $\sigma$, are retrieved from DEMs (40-m resolution in this study) to mimic the spatial distribution. In other words, each flow path has different parameters depending on the length of flow path and the physical characteristics of flow path elements. The total surface flow at watershed outlet is obtained by a convolution integral of the flow response from all grid cells. 
For inter flow, $Q_{i}\left[\mathrm{~L}^{3} / \mathrm{T}\right]$, we followed the formula in original TOPMODEL:

$Q_{i}=Q_{i 0} \exp \left(-m_{i} \bar{S}_{2}\right)$,

where $\left[\mathrm{L}^{3} / \mathrm{T}\right]$ is defined as a outflow parameter related to soil hydraulic properties and topography. In fact, $Q_{i 0}$ is the discharge when average soil moisture deficit equals zero. $A$ is the watershed area and $m_{i}$ is the recession coefficient of inter flow associated with soil characteristic. Parameter, $\lambda$, the averaged soil-topographic index of the entire watershed, is defined as

$\lambda=\frac{1}{A} \sum_{i} A_{i} \cdot \ln \frac{a_{i}}{T_{i} \tan \beta_{i}}$,

where $A_{i}, a_{i}, \beta_{i}$, and $T_{i}$ are cell area, specific contributing area, local slope, and local transmissivity, respectively, for inter flow associated with the $i$ cell. $\bar{S}_{2}$ is the average of soil moisture deficit for the entire watershed. The soil moisture deficit is the reduced moisture deficit per unit volume of soil from saturation (Walter et al., 2002),

$S_{2}=1-\frac{\theta-\theta_{d}}{\theta_{s}-\theta_{d}}$,

where $\theta$ is the average soil moisture content, $\theta_{s}$ is the saturated soil moisture content and $\theta_{d}$ is the air dry soil moisture content. Following the steady state assumption in TOPMODEL, the soil moisture deficit for each grid is

$S_{2, i}=\bar{S}_{2}+\frac{1}{m_{i}}\left[\lambda-\ln \left(\frac{a_{i}}{T_{i} \tan \beta_{i}}\right)\right]$,

where $S_{2, i}$ is the soil moisture deficit for $i_{t h}$ cell. The specific contributing area is derived from the infinite flow direction (Tarboton, 1997). Meanwhile the local slope gradient, $\beta_{i}$ is calculated by Zevenbergen and Throne's method (1987). $T_{i}$ is the local transmissivity for inter flow defined as the integral of hydraulic conductivity and soil depth.

The watershed average soil moisture deficit for each time step is updated by calculating the input and output in time steps,

$$
\begin{aligned}
\bar{S}_{2, t} & =\bar{S}_{2, t-1}+\left(Q_{i, t-1}-Q_{v, t} / A\right) \\
Q_{v} & =\sum_{i} q_{R v, i} \cdot A_{i}
\end{aligned}
$$

where $Q_{v}$ is the total recharge to the middle layer in each time step. At time $t=0$, the initial $\bar{S}_{2}$ is estimated by

$\bar{S}_{2, t=0}=-\frac{1}{m_{i}} \ln \left(\frac{0.2 \cdot Q_{\mathrm{obs}, t=0}}{Q_{i 0}}\right)$,

where $Q_{\mathrm{obs}, t=0}$ is the observed discharge at time $t=0$. Note that the proportion of inter flow over total stream discharge in the initial condition is assigned to be 0.2 . Once the initial catchment average soil moisture deficit is decided, the spatial pattern is implanted by Eq. (7). Some other methods had been proposed to replace Eq. (7) to mimic the spatial pattern, such as Troch et al. (1993) and Barling et al. (1994). Since we focus on the applicability of this TOPMODEL, the original implement is applied.

For base flow calculation, we applied the exponential recession curve function (Lamb and Beven, 1997),

$Q_{b}=Q_{b 0} \exp \left(-m_{b} \cdot \bar{S}_{3}\right)$

where $m_{b}$ is the recession coefficient and $Q_{b 0}$ is the discharge when the base flow storage deficit equals zero. Note that $Q_{i 0}$ and $Q_{b 0}$ are different owing to different transmissivity, but share the same $K$ and $D$. Similar to inter flow, the base flow deficit is also updated in each step by following water balance,

$\begin{aligned} \bar{S}_{3, t-1} & =\bar{S}_{3, t-1}+\left(Q_{b, t-1}-Q_{p, t} / A\right) \\ Q_{p} & =\sum_{i} P_{i} \cdot A_{i}\end{aligned}$,

where $Q_{p}$ is the total recharge from the middle layer to the saturated zone. Note that only when the cell in the middle layer is saturated, the percolation, $P[\mathrm{~L} / \mathrm{T}]$, will recharge the bottom layer. Besides, the initial bottom layer storage is represented as

$\bar{S}_{3, t=0}=-\frac{1}{m_{b}} \ln \left(\frac{0.8 \cdot Q_{\mathrm{obs}, t=0}}{Q_{b 0}}\right)$.

Thus the three flows can be simulated step by step when hourly rainfall inputted.

Collectively, eight global parameters in functions aforementioned are essential to route the model: maximum storage $\left(S_{1 \max }\right)$ in the upper layer, initial value of $\left(S_{10}\right)$, surface roughness $(n)$, soil characteristic parameter $\left(m_{i}\right)$, saturated hydraulic conductivity $(K)$, soil depth $(D)$, base flow recession coefficient $\left(m_{b}\right)$, and percolation rate $(P)$. The main model outputs for each time step include the spatial pattern of soil moisture for the entire watershed and stream discharge at outlet, which composes of simulated surface flow, inter flow and base flow.

TOPMODEL is a spatially distributed model. Many previous studies utilized the capacity and applied the land cover map, vegetation cover and soil map to represent the parameter distribution in space. Those kind of distributed maps introduce their ordinary-scale (classification) information; however, converting these categories into parameter values (interval- or ratio-scale) is highly uncertain (Wang et al., 2006) and case dependent. It may also raise the fog of equifinality as well (Beven and Freer, 2001). Moreover, some model parameters only represent conceptual entities, which may not be measured directly (Refsgaard et al., 2006). For example, soil transmissivity in TOPMODEL has been proven that it is a scale parameter with grid size (Franchini et al., 1996).

To reduce complexity of heterogeneity, all parameters are assumed homogeneous. This uniform assumption may hold because $90 \%$ of the areas are covered by forest. 


\subsection{Parameter calibration and performance measure}

Parameter calibration is essential because of the limitations of model structure and data availability of parameters, namely, initial conditions and boundary conditions. During calibration various measures were proposed to quantify the performance of hydrological simulation. Those measures depend on different purposes such as hydrograph shape, peak flow, peak time, discharge volume or even low flow (e.g. Krause et al., 2005). Different measures, apparently, extract different satisfactory combinations for their own aspect.

Here, we combine the overall root mean square error (ORMSE) and average root mean square error of peak flow (ARMSE) with equal weights (Madsen, 2000) to serve as our performance measure (CRMSE). The following formulas define ORMSE, ARMSE, and CRMSE:

ORMSE $=\left[\frac{\sum_{i=1}^{N} w_{i}^{2}\left[Q_{s, i}-Q_{o, i}\right]^{2}}{\sum_{i=1}^{N} w_{i}^{2}}\right]^{1 / 2}$,

$\mathrm{ARMSE}=\frac{1}{M_{p}} \sum_{j=1}^{M_{p}}\left[\frac{\sum_{i=1}^{n_{j}} w_{i}^{2}\left[Q_{s, i}-Q_{o, i}\right]^{2}}{\sum_{i=1}^{n_{j}} w_{i}^{2}}\right]^{1 / 2}$,

$\mathrm{CRMSE}=\frac{1}{2} \mathrm{ORMSE}+\frac{1}{2} \mathrm{ARMSE}$

In Eqs. (13)-(15), $Q_{o, i}$ is the observed discharge at time $i$, $Q_{s, i}$ is the simulated discharge, $N$ is the total time step in the individual events, $M_{p}$ is the number of peak flow events, $n_{j}$ is the number of time steps in peak flow periods and $w_{i}$ is the weighting function. Peak flow periods are defined as periods when the observed discharge is $>100 \mathrm{~m}^{3} / \mathrm{s}$. This measure concerns both hydrograph shape and peak flow that are most important for flood warning.

To present differences between simulation and observation, we further provide 5 indicators, namely, $\mathrm{EC}, \mathrm{EC}_{\log }$, EQV, EQP, and EQT. All five indicators are often used in evaluating hydrograph simulation. The efficiency coefficient (EC) proposed by Nash and Sutcliffe (1970) can quantify the overall deviation between simulated and observed hydrographs. The highest value of EC is 1.0. To better quantify the similarity in low flow condition, $\mathrm{EC}_{\mathrm{log}}$, the logarithmic Nash-Sutcliffe efficient (e.g. Güntner et al., 1999; De Smedt et al., 2000), is applied due to its ability to reproduce time evolution of low flow. The other three indicators: the error of total discharge volume (EQV) is defined as the ratio of simulated total flow over observed total flow; the error of peak flow (EQP) is defined as the ratio of simulated peak flow over observed peak flow, and the error of time to peak (EQT) is defined as the deviation between times of simulated peak and observed peak. Through the five indicators the performance of simulations can be evaluated comprehensively.

To extract the global best-fitted combination, 20000 parameter sets are generated by random uniform-distribution generator (Table 2). The uniform distribution is generally adapted for generating parameters when information about the parameter population is insufficient. Based on the 20000 parameter combinations, 20000 predictions and correspondent CRMSE values for each event are acquired. Among the 20000 predictions we obtain the best-fitted combination (with lowest CRMSE value) for each event individually. However, the best-fitted combination may not be the best for the other events; therefore all CRMSE values are summed to evaluate the overall performance of the respective parameter set. This overall performance serves as a criterion to single out the global best-fitted combination.

\section{Results and discussion}

\subsection{Best-fitted simulation and calibration}

Simulations derived from the global best-fitted and the event best-fitted combination are compared by using the 5 indicators mentioned above (Table 3 ). For individual event, bestfitted EC varies from 83.3 97.3\% with an average EC of $91.0 \%$. $\mathrm{EC}_{\log }$ values range from 89.5 to $98.3 \%$ with an average of $96.2 \%$. The means of absolute value of EQV and EQP are $7.6 \%$ and $10.4 \%$, respectively. Generally speaking, the near-perfect simulation can be derived from specific combination. However, those different combinations may not be the same and cannot be used for validation and practical applications.

Contrast to individual results, those simulations based on the global best-fitted combination: $n=0.13, S_{1 \max }=14.9 \mathrm{~mm}$, $S_{10}=15.9 \mathrm{~mm}, m_{i}=80.2, D=3.1 \mathrm{~m}, K=130 \mathrm{~mm} / \mathrm{h}, m_{b}=22.1$, $P=4.6 \mathrm{~mm} / \mathrm{h}$ are also presented. EC values of simulations derived from global best-fitted set vary from 59.8 to $96.6 \%$ with an average of $82.4 \%$, which is lower than independent simulations (Table 3). The global best-fitted set gives $\mathrm{EC}_{\log }$ values from 81.2 to $99.0 \%$ with an average of $93.7 \%$. Meanwhile, the means of absolute value of EQV and EQP are $13.2 \%$ and $13.1 \%$, respectively. The standard deviations of $\mathrm{EC}, \mathrm{EC}_{\log }$, EQV, and EQP are 11.0, 5.5, 18.5, and 12.3, respectively. Such result illustrates the global best-fitted set can give consistent results for all events over a wide range of total rainfall.

Here we show six examples of simulated hydrographs derived from the global best-fitted combination (Fig. 3) to reveal the observed and simulated hydrograph features. Three common features are shown: First, for all events the observed discharge does not respond to rainfall at early stage. This phenomenon is typical in forested watersheds due to water detention or interception by intensive vegetation. Second, both surface flow and inter flow, which predominate over the 
Table 2. The description, sampling range, and distribution of the 8 input parameters.

\begin{tabular}{|c|c|c|c|}
\hline Parameter & Definition and unit & Range & Distribution \\
\hline$n$ & surface roughness, [-] & $0.08 \sim 0.22$ & Uniform \\
\hline$S_{1 \max }$ & $\begin{array}{l}\text { maximum storage in } \\
\text { upper layer, [mm] }\end{array}$ & $1.0 \sim 50.0$ & Uniform \\
\hline$S_{10}$ & $\begin{array}{l}\text { initial upper } \\
\text { layer storage, }[\mathrm{mm}]\end{array}$ & $1.0 \sim 50.0$ & Uniform \\
\hline$m_{i}$ & $\begin{array}{l}\text { recession coefficient } \\
\text { of inter flow, }\left[\mathrm{m}^{-1}\right]\end{array}$ & $20 \sim 120$ & Uniform \\
\hline$D$ & soil depth, $[\mathrm{m}]$ & $0.5 \sim 5.0$ & Uniform \\
\hline $\log (K)$ & $\begin{array}{l}\text { saturated hydraulic } \\
\text { conductivity, }[\mathrm{mm} / \mathrm{h}]\end{array}$ & $-3.0 \sim 3.0$ & Uniform \\
\hline$m_{b}$ & $\begin{array}{l}\text { recession coefficient } \\
\text { of base flow, }\left[\mathrm{m}^{-1}\right]\end{array}$ & $20 \sim 60$ & Uniform \\
\hline$P$ & percolation rate, $[\mathrm{mm} / \mathrm{h}]$ & $0.1 \sim 10.0$ & Uniform \\
\hline
\end{tabular}

hydrograph, respond rapidly. Surface flow dominates particularly under torrential and concentrated rainfall conditions, such as event 1, 7, and 11 (Fig. 3a, d, and f), whereas, the inter flow dominates when the rainfall is relative small and gentle, such as Events 3 and 9 (Fig. 3b and e). Obviously, rainfall characteristics may regulate the relative contribution of surface flow and inter flow in model. Third, the base flow, which occupies a relatively small portion of total discharge, always shows slow response.

Honestly, although we have good performances in using the 3-layer TOPMODEL, geochemical tracers or other advanced techniques are still needed to validate the three flow components. Note that many hydrological models based on different runoff generation mechanism or different storages can also give equal performances (Beven and Freer, 2001; Steenhuis et al., 1999) after calibration, so called equifinality. Apparently, it is insufficient that only using stream discharge to evaluate runoff generation mechanism and storages. In our case, nevertheless, the calibrated saturated hydraulic conductivity $(130 \mathrm{~mm} / \mathrm{h})$ is higher than the maximum rainfall intensity. Such higher $K$ might indirectly support saturation excess runoff mechanism in subtropical mountainous watersheds as indicated by Walter et al. (2003). Meanwhile, no Hortonian flow was observed in the field during our typhoon monitoring in 2007. In addition, our preliminary result of geochemical tracers (unpublished data) suggests three components in stream discharge. Those indirect evidences support the potential of 3-layer structure for this kind of watershed.

\subsection{Validation and inter-comparison among events}

After calibration, the global best-fitted combination is applied onto validation events and the simulations are presented in Table 4. The EC values vary from 57.1 96.2\% with an average of $80.1 \%$. The $\mathrm{EC}_{\log }$ values range from $88.5 \sim 98.0 \%$ with an average of $93.8 \%$. Meanwhile, the means of absolute values of EQV and EQP are 15.0 and $16.4 \%$, respectively, with ranges of $-21.2-+33.2 \%$ and $-34.7-+4.4 \%$. And the standard deviations of $\mathrm{EC}, \mathrm{EC}_{\mathrm{log}}, \mathrm{EQV}$, and $\mathrm{EQP}$ are 13.2, $4.5,18.1$, and 10.8 , respectively.

For validation events, 6 examples of simulated hydrographs are shown in Fig. 4. The features of the simulated hydrographs resemble those presented in Fig. 3. Since selected events cover a wide range of total rainfall, we compare the four indicators against the total rainfall (Fig. 5). Most validation events fall within \pm 1 standard deviation of respective indicator indicating that the overall performances of validation events are similar to those of calibration events. In addition, this figure also shows the performances are irrelative to total rainfall. Thus we have confidence to apply our model for various rain storms for management.

However, there are still some events falling out of \pm 1 standard deviation. For example, those events hold two-peak rainfall pattern with the second peak smaller in observation (Events 5, 11, and 16). Yet, sometimes the second peak in simulation is larger than the first peak. The cause for such decoupled rainfall-runoff response remains unknown and apparently it cannot be simulated by models if the decoupling is real. Heterogeneous rainfall spatial pattern is plausible, that is, one raingauge station is insufficient though the watershed area is small. In fact, for rainfall-runoff event modeling, each event may be regarded as a unique instance and cannot be reproduced in the real world. It implies that even suffering the similar rainfall, the observed discharges may not be identical, but must be much similar in modeling. Reaney et al. (2007) concluded that storms with similar amounts of total rainfall but with varying rainfall allocation can generate very different discharge patterns, depending on the storm characteristics. Pebesma et al. (2007) applied QPBRRM, a quasi-physically based rainfall-runoff model, on R-5 catchment with 72 storm events and concluded that by considering event variables (e.g. total rainfall, rainfall intensity, runoff coefficient) the model performance can be improved significantly. These recent studies imply that the influence of storm characteristics on runoff generation may not be interpreted completely in many modern models. Other reasons, such as the uncertainty of rainfall measurement, discharge measurement and model structure may account for it. No matter what caused the rainfall-runoff decoupling our model performance is in acceptable range. 

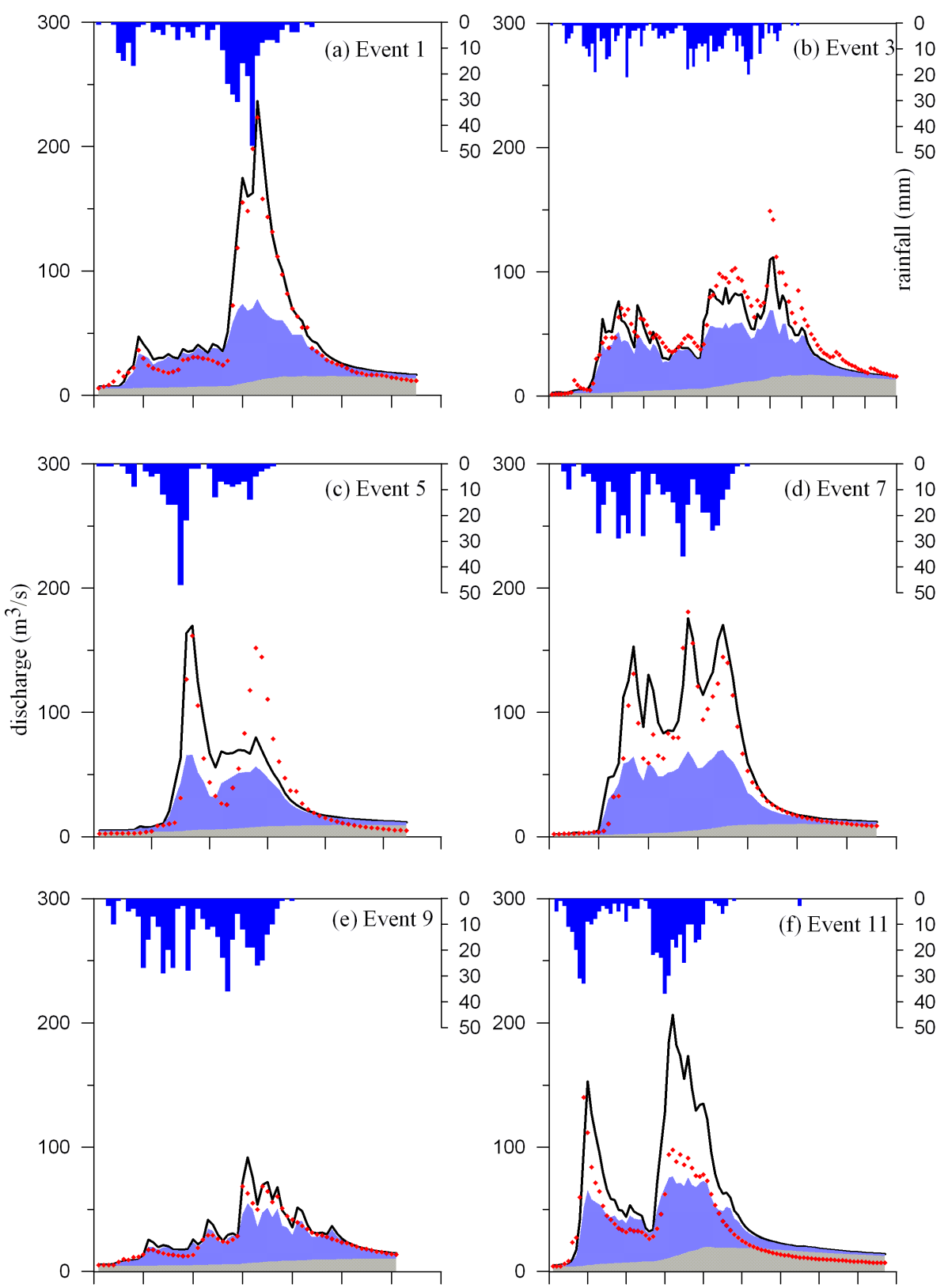

Time (hr)

Fig. 3. The 6 examples among 11 calibration events for simulated and observed hydrographs with corresponded hyetographs. The red dot stands for observation; black curve represents simulation. Gray and blue gray zones indicate, respectively, the base and inter flows.

\subsection{Parameter sensitivity in hydrograph simulation}

Though the model applicability is presented, the parameter behaviors and it effects on model efficiency are still not clear. Computation efficiency in calibration can be significantly improved if we know which parameters are most sensitive to model simulations (Sieber et. al., 2005; Tang et al., 2007).
Here a sensitivity analysis based on flow volume and Nash-Sutcliffe EC (shape likelihood) is conducted. Each single parameter changes from $-50 \%$ to $+50 \%$ while leaving the rest parameters unchanged in the global best-fitted combination to examine model responses respective to parameter changes (Fig. 6). Event 3, which holds the longest flood duration, is used as an example. We also apart total discharge into three components to investigate their responses separately. 


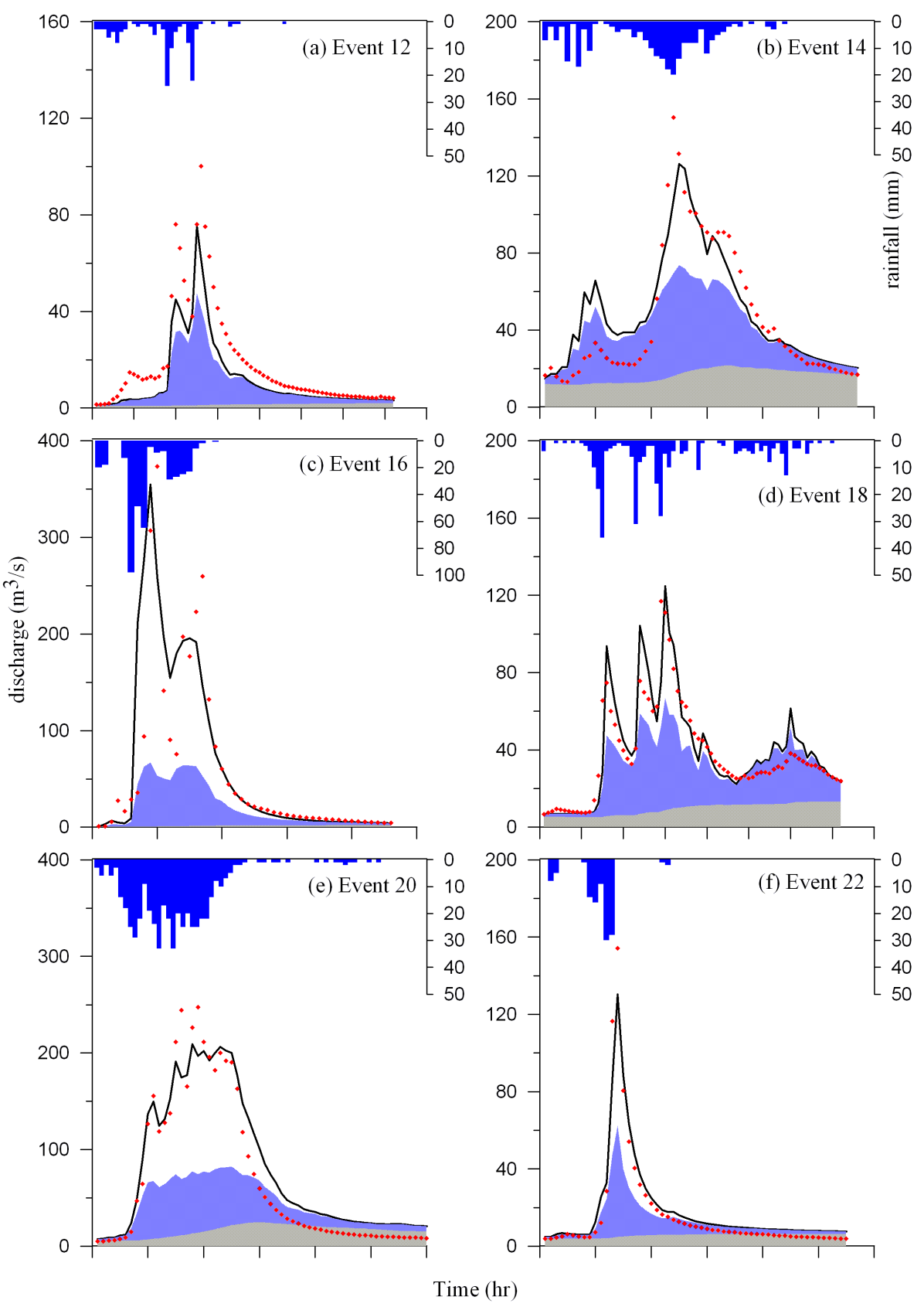

Fig. 4. The 6 examples among 11 validation events for simulated and observed hydrographs with corresponded hyetographs. The red dot stands for observation; black curve represents simulation. Gray and blue gray zones indicate, respectively, the base and inter flows.

In Fig. 6, the 6 uppermost panels are for total discharge, we can see EC value changes as parameter changes (Fig. 6.a1f1). Parameter $P$ and $m_{i}$ are the most effective on shape likelihood in terms of integrated hydrograph. However, the base flow is the most responsive component to changes in $P$ and $m_{b}$ and the subsurface flow is responsive to changes in $K, m_{i}$ and $D$. Surface roughness (n) does not alter the discharge volume and only affect the hydrograph shape in surface flow (Fig. 6a.1-4). This parameter determines surface flow's traveling time (or surface flow velocity). The smaller $\mathrm{n}$ values cause faster response and consequently sharper hydrograph. Each parameter has its own effects on EC and/or total discharge.

Total discharge responds to parameter changes except $n$. Parameters affect total discharge by different components in different ways, non-reactive, positive/negative, linear/nonlinear or mixed. For example, parameter $m_{b}$ is the most effective in term of total discharge, of which $10 \%$ discharge 
Table 3. Simulation results of the 11 calibration events by individual and global best-fitted parameter set.

\begin{tabular}{llllllllll}
\hline Event & \multicolumn{2}{c}{ EC $(\%)$} & \multicolumn{2}{c}{ EC $_{\text {log }}(\%)$} & \multicolumn{2}{c}{ EQV $(\%)$} & \multicolumn{2}{c}{ EQP $(\%)$} & \multicolumn{2}{c}{ EPT (h) } \\
& Individual & Global & Individual & Global & Individual & Global & Individual & Global & Global \\
\hline No. 1 & 97.1 & 96.6 & 97.7 & 97.9 & -0.9 & -4.0 & +0.1 & -2.3 & 0 \\
No. 2 & 76.3 & 59.8 & 92.7 & 90.0 & +8.5 & -15.5 & -28.7 & -13.3 & 0 \\
No. 3 & 95.3 & 87.7 & 98.2 & 97.4 & -0.5 & -10.2 & -19.1 & -20.9 & 1 \\
No. 4 & 89.0 & 79.7 & 98.1 & 94.8 & -3.6 & -16.1 & -5.0 & -26.7 & 1 \\
No. 5 & 83.3 & 67.0 & 94.9 & 92.0 & +1.8 & -8.5 & -3.3 & -8.8 & 0 \\
No. 6 & 88.8 & 87.9 & 89.5 & 81.2 & +30.0 & +31.4 & -17.4 & -16.9 & -1 \\
No. 7 & 93.8 & 88.8 & 97.8 & 96.9 & +2.2 & -0.1 & -4.3 & -0.9 & 8 \\
No. 8 & 95.5 & 88.7 & 97.7 & 98.3 & +7.0 & -3.3 & -9.7 & -27.0 & 1 \\
No. 9 & 94.2 & 91.8 & 98.3 & 99.0 & -4.4 & -7.4 & +3.1 & +13.3 & 1 \\
No. 10 & 97.3 & 78.7 & 95.1 & 87.8 & +11.5 & +40.4 & +6.8 & -1.7 & 0 \\
No. 11 & 90.7 & 79.5 & 97.9 & 95.7 & +13.3 & +8.5 & -17.0 & -12.0 & 23 \\
Average & 91.0 & 82.4 & 96.2 & 93.7 & $|7.6|$ & $\mid 13.2$ & $|10.4|$ & $|13.1|$ & - \\
Std. & - & 11.0 & - & 5.5 & - & 18.5 & - & 12.3 & - \\
\hline
\end{tabular}

| | stands for the absolute value.
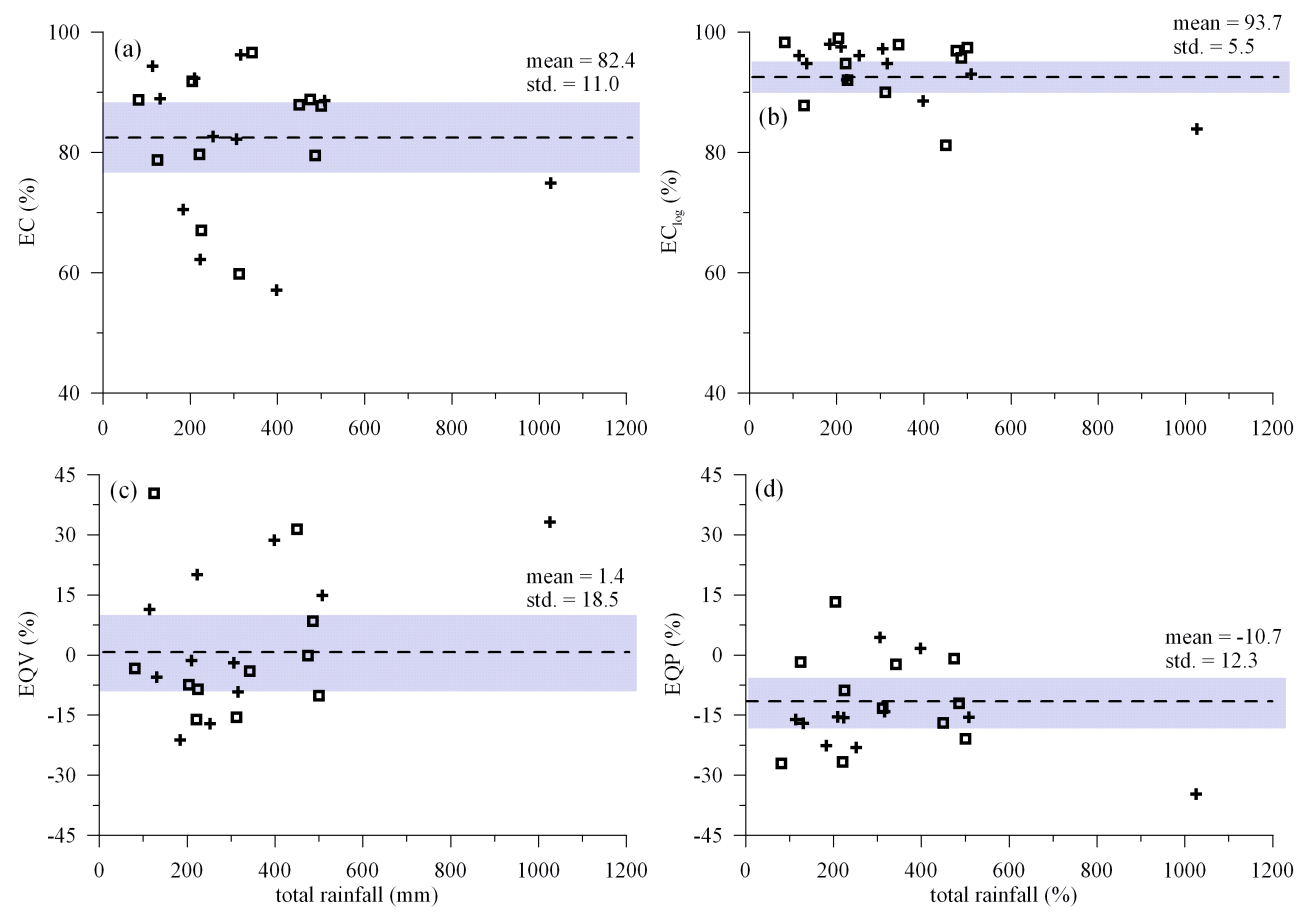

Fig. 5. Scatter plots of performance indicators against total rainfall. Dash lines and gray zones are the means and standard deviations, respectively, derived from calibration events. Squares and crosses mark, respectively, the calibration and validation events.

changes corresponds to $50 \%$ changes in $m_{b}$. However, its effect is mainly caused by changes in base flow, which composed of $\sim 30 \%$ of total discharge, thus its influence on total discharge is compromised though over $40 \%$ changes in base flow can be induced. Parameter $m_{b}$ controls the resident time in bottom layer and therefore has a significant effect on the amount of base flow but no interactive effect on surface or inter flows (Fig. 6e.2-4). In general, $m_{i}$ reflects mainly the velocity of inter flow. Higher $m_{i}$ may induce a faster change in soil moisture deficit, thus, may cause a larger saturated area to enhance the surface and base flows (Fig. 6c.2) and diminish the inter flow significantly (Fig. 6c.3).

Positive effects of $K$ and $D$ on total discharge are revealed and the response is almost the same since they together determine the soil transmissivity, thus, the surface and base flows show negative responses and subsurface flow shows positive 

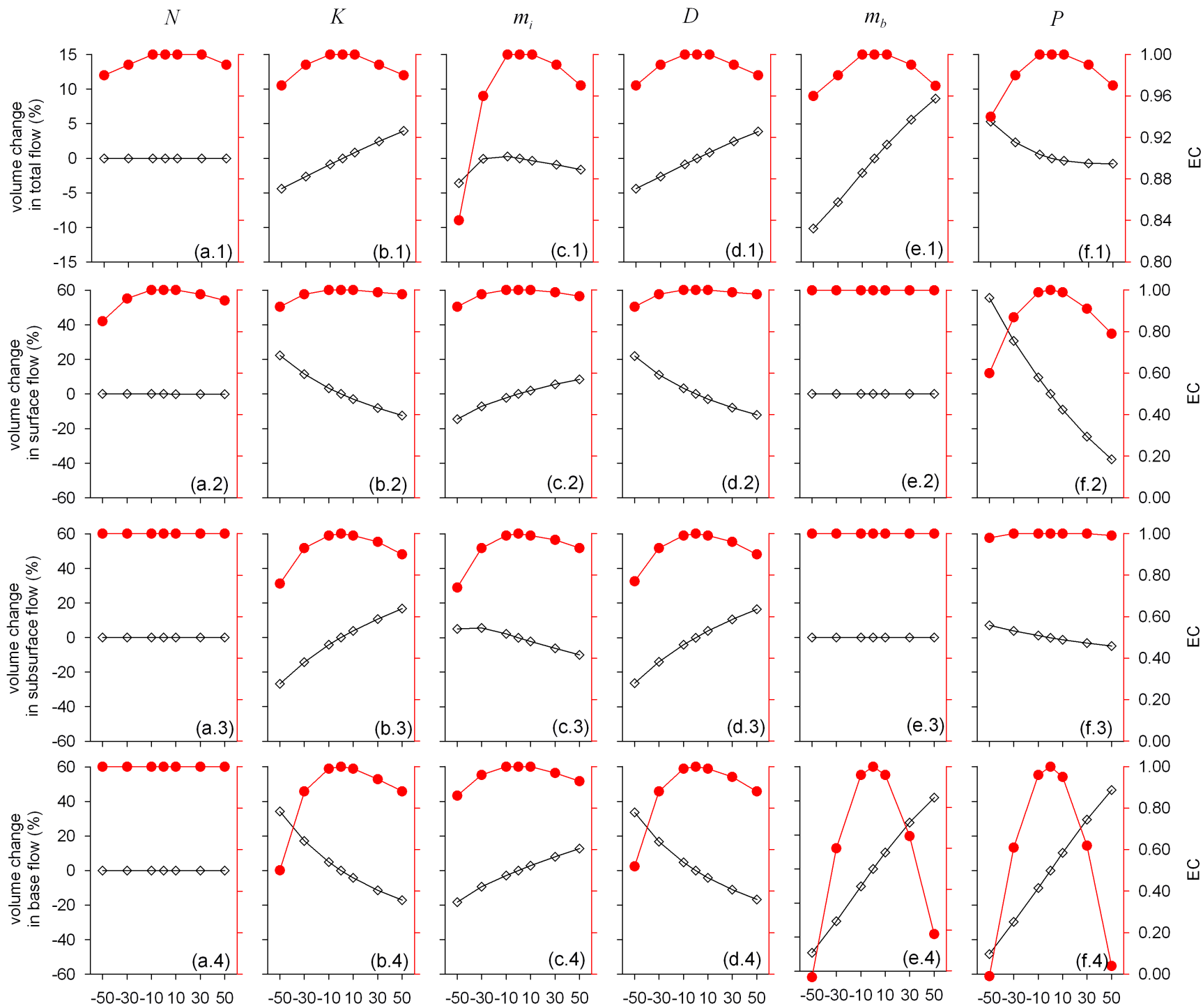

parameter change (\%)

Fig. 6. The percent change in discharge and EC response against parameter change. The $\mathrm{x}$-axis shows percent change in individual parameter based on the global best-fitted combination. Left y-axis corresponded to empty diamonds represent percent changes in discharge. Right $y$-axis corresponded to red circles stands for the percent changes in EC. Note that y-axis is in different range.

response. Higher $K$ and $D$ allow the water infiltrate to middle layer and reduce the surface and base flow (Fig. $6 \mathrm{~b}$ and d). Addition to $m_{b}, K$, and $D$, parameter $P$ is also effective on total discharge (Fig. 6 f.1-4). As $P$ increases, the surface flow volume decreases significantly. Higher $P$ diminishes the surface and inter flow and increase the base flow.

Our results of sensitivity analysis may guide the priority in field measurements and shed lights on process interactions inside models to strengthen our understanding on model structure and re-examine the rationality of model hypothesis.

\subsection{Confidence interval}

Although the simulation performances are promising, provide the confidence interval to bracket possible uncertainty is necessary for practical applications. Here we use an empirically-based method to estimate confidence interval. The main idea of this method is to quantify uncertainties by projecting residual errors in simulation onto observations, because the residual errors (differences between simulations and observations) are the best material to project uncertainties for unknown conditions. 
Table 4. Simulation results of validation events by the global bestfitted parameter set.

\begin{tabular}{llrrrr}
\hline Event & $\begin{array}{l}\text { EC } \\
(\%)\end{array}$ & $\begin{array}{r}\mathrm{EC}_{\log } \\
(\%)\end{array}$ & $\begin{array}{r}\mathrm{EQV} \\
(\%)\end{array}$ & $\begin{array}{r}\text { EQP } \\
(\%)\end{array}$ & $\begin{array}{r}\mathrm{EPT} \\
(\mathrm{h})\end{array}$ \\
\hline No. 12 & 88.9 & 94.8 & -5.5 & -17.0 & -1 \\
No. 13 & 96.2 & 94.8 & -9.2 & -14.1 & 0 \\
No. 14 & 82.6 & 96.1 & -17.1 & -23.1 & 1 \\
No. 15 & 92.3 & 97.5 & -1.4 & -15.4 & 0 \\
No. 16 & 57.1 & 88.5 & +28.6 & +1.7 & -1 \\
No. 17 & 62.2 & 92.1 & +20.1 & -15.6 & -3 \\
No. 18 & 82.2 & 97.2 & -1.9 & +4.4 & 1 \\
No. 19 & 70.5 & 98.0 & -21.2 & -22.6 & 0 \\
No. 20 & 88.6 & 93.0 & +14.9 & -15.5 & 0 \\
No. 21 & 74.9 & 83.9 & +33.2 & -34.7 & 0 \\
No. 22 & 94.3 & 96.1 & +11.4 & -16.1 & 0 \\
Average & 80.1 & 93.8 & $|15.0|$ & $|16.4|$ & - \\
Std. & 13.2 & 4.5 & 18.1 & 10.8 & - \\
\end{tabular}

Table 5. Empirically-based confident interval and success rate in validation.

\begin{tabular}{lllll}
\hline $\begin{array}{l}\text { Discharge } \\
\text { category } \\
\left(\mathrm{m}^{3} / \mathrm{s}\right)\end{array}$ & $\begin{array}{l}\text { Lower } \\
\text { limit }\end{array}$ & Median & $\begin{array}{l}\text { Upper } \\
\text { limit }\end{array}$ & $\begin{array}{l}\text { Success rate } \\
\text { in validation }\end{array}$ \\
\hline$<4.8$ & 0.60 & 1.30 & 3.54 & 0.93 \\
$4.8-7.2$ & 0.72 & 1.08 & 2.01 & 0.78 \\
$7.2-10.8$ & 0.55 & 0.89 & 1.70 & 0.88 \\
$10.8-15.6$ & 0.66 & 1.00 & 1.68 & 0.76 \\
$15.6-23.9$ & 0.41 & 0.94 & 1.45 & 0.92 \\
$23.9-33.6$ & 0.47 & 0.90 & 1.65 & 0.97 \\
$33.6-44.7$ & 0.52 & 0.88 & 1.58 & 0.92 \\
$44.7-74.5$ & 0.45 & 0.92 & 1.52 & 0.88 \\
$74.5-124.7$ & 0.40 & 0.90 & 1.40 & 0.94 \\
$>124.7$ & 0.40 & 0.94 & 1.53 & 0.98 \\
\hline
\end{tabular}

Firstly, the simulated discharges in calibration are divided into 10 categories by occurrence. Secondly, we calculate the median, $5 \%$ and $95 \%$ limits of $Q_{\text {obs }} / Q_{\text {sim }}$ ratios in each category. The two limits embrace $90 \%$ of simulations during calibration. Thirdly, we calculate the success rate in validation. Furthermore, by multiplying the simulation by the two limits we generate upper and lower boundaries of confidence for management use. Conceptually, it is without value if the confidence interval is too wide. On the other hand, we may obtain a narrow one in certain circumstance when data length is insufficiently long; it will be risky to apply the narrow one since it might give low success rate in validation. This confidence interval is empirically-based, thus, data length is crucial.

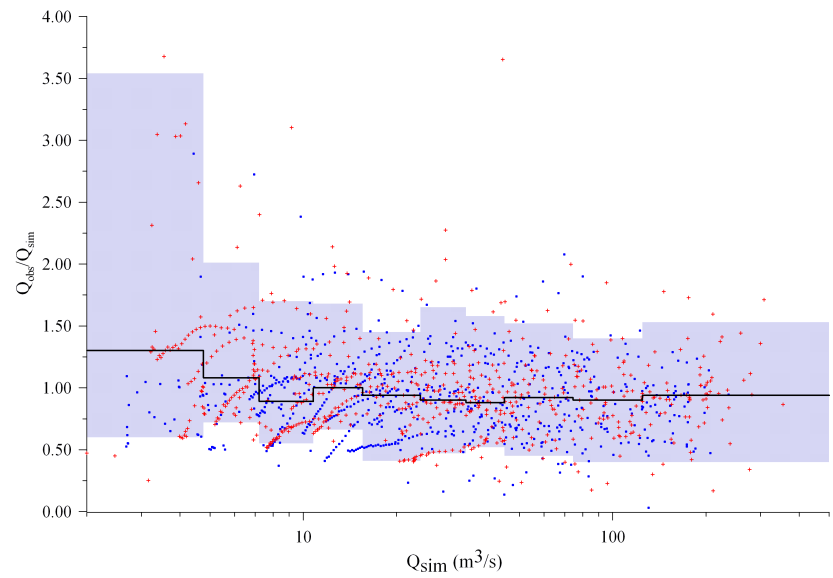

Fig. 7. Scatter plot of the $Q_{\text {obs }} / Q_{\text {sim }}$ against Qsim. Red dots stand for validation events. Black lines are the median and the gray zones are $90 \%$ confidence interval derived from all calibration events.

Here we list the medians, lower limits, upper limits, and success rate in validation for different discharge categories in Table 5. The medians of the 10 categories are close to 1.0 (except category 1 with underestimation) and the width of $90 \%$ confidence interval (upper-lower) ranges from $0.48 \sim 1.56$ (not shown). Meanwhile, mean success rate is $89.9 \pm 0.1$. Such promising results indicate that our model simulates well over wide water discharges. We also present $Q_{\text {obs }} / Q_{\text {sim }}$ ratio against $Q_{\text {sim }}$ (Fig. 7) to reveal how the empirically-based confidence interval envelope observed discharges in validation events. Our newly proposed confidence interval (Table 5) may serve as a crucial reference for future hydrograph predictions. The upper limit is suggested preferably for flood risk assessment and the lower limit preferably for drought assessment.

\section{Conclusions}

This study presents the capability of a 3-layer TOPMODEL in simulating flood hydrograph induced by wide ranges of torrential rainfalls in a subtropical mountainous watershed in Taiwan. The global best-fitted combination gives an average performance of $82.4 \%$ in $\mathrm{EC}$ and $93.7 \%$ in $\mathrm{EC}_{\log }$ for $11 \mathrm{cal}-$ ibration events and $80.1 \%$ in $\mathrm{EC}$ and $93.8 \%$ in $\mathrm{EC}_{\log }$ for another 11 validation events. Sensitivity analysis reveals that in TOPMODEL framework transmissivity and recession coefficient control, respectively, the discharge volume and shape. Empirically-based confidence interval brackets $90 \%$ observations of validation events providing upper limit as useful information for flood risk assessment and practical applications. Our study provides new information to modelers who are interested in TOPMODEL and other applications (e.g. flood forecasting, material flux estimating) in subtropical region. More chemical tracers studies are needed to re-examine 
the hydrograph compositions deepening our understanding on real rainfall-runoff response and approaching better model structure. On the other hand, the influence of storm characteristics on runoff generation should be explored to improve model performances.

Acknowledgements. This research is funded by the National Science Council of Taiwan, under the project NSC 95-2116-M001-001. The authors are also grateful to Water Resources Agency and Chun-Chiang Lin in Lan Yang Institute of Technology for providing hydrological records and computation facility. We also appreciate A. Gelfan and two anonymous reviewers for their useful comments.

Edited by: A. Gelfan

\section{References}

Barling, R. D., Moore, I. D., and Grayson, R. B.: A quasi-dynamic wetness index for characterizing the spatial distribution of zones of surface saturation and soil water content, Water Resour. Res., 30, 1029-1044, 1994.

Beven, K. J.: TOPMODEL: a critique, Hydrol. Process., 11(9), 1069-1086, 1997.

Beven, K. J.: Parameter Estimation and Predictive Uncertainty, in: Rainfall-Runoff Modelling, edited by: Beven, K. J., The Primer, WILEY, New York, 217-253, 2001.

Beven, K. J. and Freer, J.: Equifinality, data assimilation, and uncertainty estimation in mechanistic modeling of complex environmental systems using the GLUE methodology, J. Hydrol., 249, 11-29, 2001

Campling, P., Gobin, A., Beven, K., and Feyen, J.: Rainfall-runoff modeling of a humid tropical catchment: the TOPMODEL approach, Hydrol. Process., 16(2), 231-253, 2002.

Candela, A., Noto, L. V., and Aronica, G.: Influence of surface roughness in hydrological response of semiarid catchments, J. Hydrol., 313, 119-131, 2005.

Casadei, M., Dietrich, W. E., and Miller, N. L.: Testing a model for predicting the timing and location of shallow landslide initiation in soil mantled landscapes, Earth Surf. Processes, 28(9), 925950, 2003.

De Smedt, F., Liu, Y. B., and Gebremeskel, S.: Hydrological modeling on a catchment scale using GIS and remote sensed land use information, in: Risk Analysis II, edited by: Brebbia, C. A., WTI press, Southampton, Boston, 295-304, 2000.

Franchini, M., Wendling, J., Obled, C., and Todini, E.: Physical interpretation and sensitivity analysis of the TOPMODEL, J. Hydrol., 175, 293-338, 1996.

Günter, A., Uhlenbrook, S., Seibert, J., and Leibundgut, C.: Multicriterial validation of TOPMODEL in a mountainous catchment, Hydrol. Process., 13, 1603-1620, 1999.

Hamon, W. R.: Estimating potential evapotranspiration: Proceedings of the American Society of Civil Engineers, J. Hydr. Eng. Div.-ASCE, 87(HY3), 107-120, 1961.

Hornberger, G. M., Scanlon, T. M., and Raffensperger, J. P.: Modelling transport of dissolved silica in a forested headwater catchment: the effect of hydrological and chemical time scales on hys- teresis in the concentration-discharge relationship, Hydrol. Process., 15(10), 2029-2038, 2001.

Huang, J. C., Kao, S. J., Hsu, M. L., and Lin, J. C.: Stochastic procedure to extract and to integrate landslide susceptibility maps: an example of mountainous watershed in Taiwan, Nat. Hazards Earth Syst. Sci., 6, 803-815, 2006, http://www.nat-hazards-earth-syst-sci.net/6/803/2006/.

Huang, J. C. and Kao, S. J.: Typhoon-induced storm hydrograph simulations versus parameter sensitivity in a 3-layer TOPMODEL: A case study in a subtropical mountainous watershed, 4th AOGS Annual Meeting, Bangkok, Thailand, 2007.

Krause, P., Boyle, D. P., and Bäse, F.: Comparison of different efficiency criteria for hydrological model assessment, Advances in Geosciences, 5, 89-97, 2005.

Lamb, R. and Beven, K.: Using interactive recession curve analysis to specify a general catchment storage model, Hydrol. Earth Syst. Sci., 1, 101-113, 1997, http://www.hydrol-earth-syst-sci.net/1/101/1997/.

Lamb, R., Beven, K., and Myrabø, S.: A generalized topographicsoils hydrological index, in: Landform Monitoring, Modeling and Analysis, edited by: Lans, S. N., Richards, K. S., Chandler, J. H., John Wiley, Chichester, 263-278, 1998.

Li, M. H., Yang, M. J., Soong, R., and Huang, H. L.: Simulating typhoon floods with gauge data and mesoscale modeled rainfall in a mountainous watershed, J. Hydrometeorol., 6(3), 306-323, 2005.

Liu, Y. B., Gebremeskel, S., De Smedt, F., Hoffman, L., and Pfister, L.: A diffusive approach for flow routing in GIS based flood modeling, J. Hydrol., 283, 91-106, 2003.

Madsen, H.: Automatic calibration of a conceptual rainfallrunoff model using multiple objectives, J. Hydrol., 235 276-288, 2000.

Molnar, P. and Ramirez, J. A.: Energy dissipation theories and optimal channel characteristics of river network, Water Resour. Res., 34(7), 1809-1818, 1998.

Monteith, J. L.: Evaporation and environment, Sym. Soc. Exp. Biol., 19, 205-234, 1965.

Nash, J. E. and Sutcliffe, J. V.: River flow forecasting through conceptual models 1. A discussion of principles, J. Hydrol., 10, 282 290, 1970.

Pebesma, E. J., Switzer, P., and Loague, K.: Error analysis for the evaluation of model performance: rainfall-runoff event summary variables, Hydrol. Process., 21, 3009-3024, doi:10.1002/hyp.6529, 2007.

Penman, H. L.: Natural evaporation from open water, bare soil, and grass, P. Roy. Soc. Lond. A, 193, 120-195, 1948.

Reaney, S. M., Bracken, L. J., and Kirkby, M. J.: Use of the connectivity of runoff model (CRUM) to investigate the influence of storm characteristics on runoff generation and connectivity in semi-arid areas, Hydrol. Process., 21, 894-906, 2007.

Refsgaard, J.C., van der Sluijs, J. P., Brown, J., and van der Keur, P.: A framework for dealing with uncertainty due to model structure error, Adv. Water Resour., 29, 1586-1597, 2006.

Scanlon, T. M., Raffensperger, J. P., and Hornberger, G. M.: Shallow subsurface storm flow in a forested headwater catchment: Observations and modeling using a modified TOPMODEL, Water Resour. Res., 36(9), 2575-2586, 2000.

Sieber, A. and Uhlenbrook, S.: Sensitivity analysis of a distributed catchment model to verify the model structure, J. Hydrol., 310, 
216-235, 2005.

Steenhuis, T. S., Parlange, J. Y., Sanford, W. E., Heilig, A., Stagnitti, F., and Water, M. F.: Can we distinguish Richard's and Boussinesq's equations for hillslopes? The Coweeta experiment revisited, Water Resour. Res., 35(2), 589-293, 1999.

Sui, C. H., Huang, C. Y., Tsai, Y. B., Chen, C. S., Lin, P. L., Shieh, S. L., Li, M. H., Liou, Y. A., Wang, T. C. C., Wu, R. S., Liu, G. R., and Chu, Y. H.: Meteorology-hydrology study targets Typhoon Nari and Taipei Flood, Eos. T, Am. Geophys. Un., 83(24), 265-270, 2002.

Tang, Y., Reed, P., Wagener, T., and van Werkhoven, K.: Comparing sensitivity analysis methods to advance lumped watershed model identification and evaluation, Hydrol. Earth Syst. Sci., 11, 793$-817,2007$, http://www.hydrol-earth-syst-sci.net/11/793/2007/.

Tarboton, D. G.: A new method for the determination of flow directions and con tributing areas in grid digital elevation models, Water Resour. Res., 33(2), 309-319, 1997.
Troch, P. A. and De Troch, F. P.: Effective water Table depth to describe initial conditions prior to storm rainfall in humid regions, Water Resour. Res., 29(2), 427-434, 1993.

Walter, M. T., Steenhuis, T. S., Mehta, V. K., Thongs, D., Zion, M., and Schneiderman, E.: Refined conceptualization of TOPMODEL for shallow subsurface flows, Hydrol. Process., 16, 2041-2046, 2002.

Walter, M. T., Mehta, V. K., Marrone, A. M., Boll, J., GerardMarchant, P., Steenhuis, T. S., and Walter, M. F.: Simple Estimation of Prevalence of Hortonian Flow in New York City Watersheds, J. Hydrol. Eng., 8(4): 214-218, 2003.

Wang, Y. C., Han, D., Yu, P. S., and Cluckie, I. D.: Comparative modeling of two catchments in Taiwan and England, Hydrol Process., 20(20), 4335-4349, 2006.

Wu, L., Wang, B., and Geng, S.: Growing typhoon influence on east Asia, Geophys. Res. Lett., 32(18), L18703, doi:10.1029/2005GL022937, 2005.

Zevenbergen, L. W. and Throne, C. R.: Quantitative analysis of land surface topography, Earth Surf. Processes, 12, 47-56, 1987. 